\title{
The Production of Aspect by L1 Learners of Greek
}

\author{
Maria Kaltsa \\ Aristotle University of Thessaloniki \\ mkaltsa@enl.auth.gr
}

\section{Abstract}

This study examines the production of aspect and telicity by children acquiring Greek as a native language. Telicity is compositionally determined by the aspectual class of the verb, morphological aspect and the presence of a quantized object. A sentence is assumed to refer to a telic event if the event is represented as having an endpoint beyond which the event cannot continue (Depraetere 2007). The aim of the present study is to identify the nature of the relation between aspect and telicity by comparing evidence drawn from the developmental steps monolinguals take in expressing telicity in activity and motion events.

\section{Introduction}

Telicity lies at the syntax-discourse interface and is determined by the interaction of different factors, that is (a) the aspectual class of the verb (cf. Vendler 1967, Dowty 1979, Smith 1991, Ramchand \& Svenonius 2002, Rothstein 2002), (b) morphological aspect and (c) the presence or absence of objects and particles (cf. van Hout 2003), where factors (b) and (c) are language specific. The interaction of these factors offer information about the internal temporal organisation of an event and lead to a compositional understanding of aspectual meaning. Telicity being a by-product of the aspectual marking of VPs has been controlled by a variety of language-specific criteria such as the adverbial modification test, the conjunction test and the progressive entailment test (see Borik 2006).

Vendler's classification of verbs distinguishes between states and activities being atelic from achievements and accomplishments being telic (Vendler 1967, Dowty 1979). Smith (1991) discusses the shift from one situation type (i.e. aspectual verb class) to the other as in build, an activity, to build a house, an accomplishment. This shift renders the atelic verb into a telic predicate. A

\section{(cc) BY-NC-ND}


sentence receives a telic interpretation if the event is represented as having an endpoint beyond which the event cannot continue (Depraetere 2007). The manifestations of an endpoint in Depraetere's view are the lexical semantics of the verb, (e.g. find, sneeze, explode), contextual knowledge shared by discourse participants (e.g. He sang. understood as He sang a song), specific object NPs which provide the natural endpoint to the situation or via the inclusion of a cardinal number (e.g. drink a glass of wine) and the presence of a PP-GOAL which acts as a boundary of the action denoted by the verb (e.g. He drove the car into the garage).

In Greek, the visibility of the endpoint may be established within the sentence and prior to pragmatic interpretation through lexical and grammatical means. For example, the Greek sentence Zografise ena portreto ("He painted a portrait") is unambiguously telic in that the portrait is completed while the sentence Zografize ena portreto ("He was painting a portrait") leaves open the possibility that the portrait is still not completed (Tsimpli \& Papadopoulou 2006). The difference lies on the aspectual marking of the VP. Since perfectivity makes visible the endpoint of the event (Smith 1991) the presence of the object serves to identify the endpoint with the completion of the object painting event. The imperfective aspect, on the other hand, does not make visible the endpoint of the event and leaves open the possibility of identifying the completion. Thus, in Greek telicity can be unambiguously defined within the sentence with the combination of perfective aspect and a specific object DP (cf. Mozer 1994; Chila-Markopoulou \& Mozer 2001). Furthermore, even when telicity is unambiguously defined within the sentence, this is the result of a compositional interpretation of the aspectual form and the quantized object or a PP-GOAL.

In line with Zubizarreta $\&$ Oh (2007), we assume that motion verbs may include an inherent 'directed motion' feature by selecting a PP-GOAL complement. Consider the following examples:

(1) a. To agori etrehe stin kuzina. the boy ran-IMP in-the kitchen "The boy was running in/towards the kitchen.

b. To agori etrekse stin kuzina. the boy ran-PERF in-the kitchen "The boy ran into/towards/inside the kitchen."

Each of the two sentences in ( $1 a)$ and ( $1 b)$ is ambiguous between a telic and an atelic interpretation. Specifically, in (1a) the PP stin kuzina can be construed as the GOAL argument or as the LOCATIVE modifier of the motion event. In (1b), on the other hand, the ambiguity increases since the telic interpretation in which the PP-GOAL is interpreted as the endpoint of the 
event is also available. Thus, in (1a) the event is unbounded and therefore atelic while in (1b) the telic interpretation is also available. Despite the ambiguity just described, native speakers develop a strong preference for the atelic locative interpretation in (1a) and the telic in (1b) (Tsimpli $\&$ Papadopoulou 2009). These preferences are associated with the aspectual distinction on the verb form in each case.

Studies in first language acquisition have shown that telicity particles in languages such as Dutch are acquired early (van Hout 1998, 2000). Van Hout $(1998,2000)$ tested typically-developing Dutch children on the comprehension of telicity showing that by age 3 children have acquired the telic interpretation of particle verbs in Dutch. Wagner (2010) reviews the evidence for the acquisition of telicity in various languages and suggests that initially children show a preference for mapping telicity onto aspectual morphemes, particles or PPs. This preference extends to associating goal-oriented interpretations with transitivity. Wagner (2006) included directed motion verbs with a goal PP in the acquisition study and found that even the youngest children (2-year olds) were accurate in interpreting telicity when a PP-GOAL was included in the sentence.

In L1 Greek, Kaltsa's comprehension study on telicity (2012) shows that (a) perfective activity VPs with a DP complement precede perfective motion VPs with a PP complement in development; and (b) the interpretation of telicity becomes adult-like between 7 to 8 years old. The delay in the Greek data compared to findings in other languages such as Dutch (van Hout 1998, 2000) and German (Schultz \& Wittek 2003), where the age of 3 is considered a turning point in the acquisition of telicity, can be attributed to the fact that telicity is not lexicalized in Greek and maintains an interface status.

\section{Predictions}

The aim of the empirical study is to investigate the role of the aspectual verb form (Perfective vs Imperfective) and the nature of the complements (DPs vs PPs) in the production of activity and motion VPs by monolingual Greek children and adults. We adopt the notion that the acquisition of syntax precedes the acquisition of features that lie at the syntax-discourse interface; the acquisition of morphological aspectual distinctions is in place by the age of 3 (Katis 1984, Tsimpli 1996). Consequently, the acquisition of the morphosyntax of aspect precedes the acquisition of telicity which is determined at the interface level. The working hypotheses are that a) activity verbs will precede motion verbs in acquisition as a result of the complements they receive and b) imperfective motion verbs will be acquired earlier than perfective ones due to the underspecification of telicity in the latter. 


\section{The Production Study}

\subsection{Participants}

Five groups of monolingual learners of Greek participated in the study. There were 250 participants in total aged from 5 to 10 years old. For each age group there were 50 participants. At the time of testing the 5-6 yrs old group had a mean age of 5;5 (Female: 21 \& Male: 29), the 6-7 yrs old group a mean age of 6;5 (Female: 23 \& Male: 27), the 7-8 yrs old one a mean age of 7:5 (Female: 26 \& Male: 24), the 8-9 yrs old group a mean age of 8;6 (Female: $24 \&$ Male: 26$)$ and the 9-10 yrs old group a mean age of 9;3 (Female: 26 \& Male: 24). All participants were typically developing learners of Greek and did not suffer from any language or mental disorder. Additionally, a group of 40 adult native speakers of Greek with a mean age of 36;7 (Female: 27 \& Male: 13) was included for control purposes.

\subsection{Materials}

The production task consisted of 64 short video stimuli. For each verb, we constructed two videos, one presenting a telic/complete event and the other depicting an atelic/ongoing event. To avoid repetition effects two versions of the task were created with 32 video stimuli each, so that the participants never saw the same verb-event/video more than one time in each session. There were 18 target verbs ( 6 intransitive, 6 activity and 6 motion verbs) and 14 filler verbs. The activity verbs were zografizo ('paint'), dhiavazo ('read'), troo ('eat'), pino ('drink'), katharizo ('clean') and ftiahno ('make'). The motion verbs were strifogirizo ('turn around'), sernome ('crawl'), treho ('run'), pidho ('jump'), pigeno ('go') and horopidho ('gambol'). The test verbs were selected on the basis of the results of two pretasks, an acceptability judgment task and a verb frequency task (for a detailed account see Kaltsa 2012: 114-118).

\subsection{Procedure}

The participants were shown one video at a time presenting either the telic or atelic condition and a test question followed. The test question was not morphologically marked with aspect (2) and it included a time adverbial to indicate past reference:

(2) $\mathrm{T}$ i $\dot{\kappa} \kappa \alpha v \varepsilon \quad \chi \theta \varepsilon \varsigma \quad$ to $\pi \alpha 1 \delta i ́ ;$ what do-PAST yesterday the-NOM child "What did the child do yesterday?" 
The task for the participant was to describe the event. Examples of each targeted VP construction may be seen in (3) and (4):

(3) Activity VP
(a) Hthes to koritsi efage ena milo. yesterday the girl eat-PERF an apple 'Yesterday the girl ate an apple.'
(b) Hthes to koritsi etroge ena milo. yesterday the girl eat-IMP an apple 'Yesterday the girl was eating an apple.'

(4) Motion VP
(a) Hthes to agori etrekse sti kuzina. 'Yesterday the boy ran to the kitchen.' yesterday the boy run-PERF o/in the kitchen yesterday the boy run-IMP inside the kitchen 'Yesterday the boy was running in the kitchen.'
(b) Hthes to agori etrehe sti kuzina.

In (3a), the perfective activity VP was considered as a target utterance for a telic event, that is a completed event where the goal has been accomplished (the whole apple has been consumed). In the case of the imperfective activity VP (3b), the utterance was accepted as a description of an atelic event during which the goal has not been achieved (the apple remains uneaten). In (4a), the perfective motion VP with a PP-GOAL was considered as a target utterance for a telic motion event. In the case of the imperfective motion VP (4b), the utterance was accepted as a description of an atelic event.

\subsection{Results}

For the data analysis of the production experiment we filtered out utterances that were not morphological marked as past and / or were not lexically related to the verb-target. For the rest of the responses we examined the use of perfective and imperfective aspectual verb forms and the use of overt or null DPs and PPs for activity and motion verbs respectively when describing telic events.

Activity Events and Aspect

For the event type comparisons (telic vs. atelic) in the aspectual marking of activity verb constructions we performed two-way group-independence chisquare tests. The comparisons show that the event type the participants were shown significantly affects the aspectual choice of the 7 yrs old and older 
children. Adults also show this effect. The two youngest age groups, though, do not appear to be equally sensitive to the role of telicity (5-6 yrs old: $\chi^{2}=.669$, $\mathrm{df}=1, \mathrm{p}=.413 ; 6-7$ yrs old: $\chi^{2}=.500, \mathrm{df}=1, \mathrm{p}=.480 ; 7-8$ yrs old: $\chi^{2}=7.386, \mathrm{df}=1$, $\mathrm{p}=.007 ; 8-9$ yrs old: $\chi^{2}=9.589, \mathrm{df}=1, \mathrm{p}=.002 ; 9-10$ yrs old: $\chi^{2}=127.396, \mathrm{df}=1$, $p=.000 ;$ Adults: $\chi^{2}=25.794, \mathrm{df}=1, \mathrm{p}=.000$ ).

Figure 1 presents the percentages of the aspectual marking for activity VPs of each age group when they were provided with a telic event.

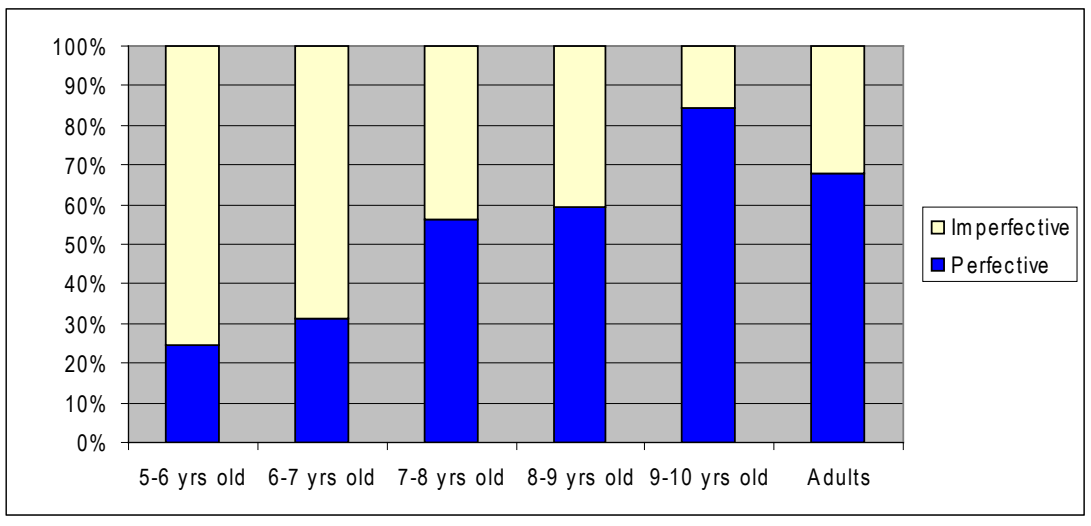

Figure 1. Aspectual Marking: Activity Telic Events

The data reported in Figure 1 show that the 5-6 yrs old group along with the 6-7 yrs old group regardless of the fact that they are given a telic event they significantly prefer to use imperfective aspect. The 7-8 yrs old group appears to be undetermined and performs at chance level. The 8-9 and 9-10 yrs old groups, however, show adult-like performance in selecting perfective aspect to describe telic events. These observations were statistically supported by oneway-goodness-of-fit chi-square tests ( $5-6$ yrs old: $\chi^{2}=32.508, \mathrm{df}=1, \mathrm{p}=.000 ; 6-7$ yrs old: $\chi^{2}=16.078, d f=1, p=.000 ; 7-8$ yrs old: $\chi^{2}=2.032, d f=1, p=.154 ; 8-9$ yrs old: $\chi^{2}=4.829, \mathrm{df}=1, \mathrm{p}=.028 ; 9-10$ yrs old: $\chi^{2}=71.201, \mathrm{df}=1, \mathrm{p}=.000$; Adults: $\chi^{2}=14.286, \mathrm{df}=1, \mathrm{p}=.000$ ). These findings indicate that perfective aspect is used to mark telicity for activity VPs.

Turning to the atelic condition, Figure 2 presents the percentages of the aspectual choice for activity VPs of each age group when they were presented with an atelic event.

The data reported in Figure 2 show that all groups uniformly select imperfective aspect to describe atelic activities. This observation was statistically supported by one-way-goodness-of-fit chi-square tests ( $5-6$ yrs old: $\chi^{2}=23.403$, $\mathrm{df}=1, \mathrm{p}=.000 ; 6-7$ yrs old: $\chi^{2}=23.432, \mathrm{df}=1, \mathrm{p}=.000 ; 7-8$ yrs old: $\chi^{2}=5.568, \mathrm{df}=$ $1, p=.018 ; 8-9$ yrs old: $\chi^{2}=4.761, d f=1, p=.029 ; 9-10$ yrs old: $\chi^{2}=56.427, d f=1$, 
$p=.000 ;$ Adults: $\chi^{2}=11.571, d f=1, p=.001$ ). It appears that imperfective aspect is mapped on atelicity for activity verb constructions early on in acquisition.

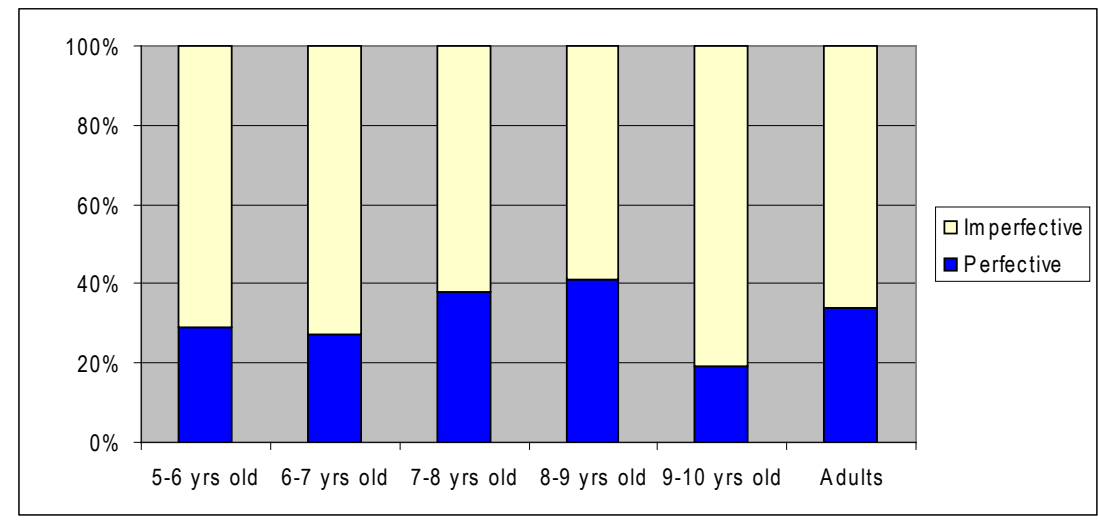

Figure 2. Aspectual Marking: Activity Atelic Events

The between group comparisons for the telic condition show very clearly the developmental steps of telicity in the aspectual marking of activity VPs. The 5-6 and 6-7 yrs old children perform alike and the 7-8 and 8-9 yrs old ones similarly to each other. When compared to adults, children are found not to have attained the target performance with the exception of the 8-9 yrs old group. Quite importantly, the differences to the adult performance are not always in the same direction for all child groups. The youngest groups' (5-8 yrs old) use of imperfective is high but it gradually lowers getting closer to the adult preference for perfective. The oldest group (9-10 yrs old), on the other hand, is significantly different to adults not because it selects the non-target aspect, that is imperfective, but due to the fact that it selects perfective aspectual marking more robustly. Thus, it is in the same direction with adults mapping telicity on perfective activities. In the atelic condition, the differences among the groups are more subtle and the preferences of each groups uniform.

To summarize, the examination of aspectual marking for activity verbs makes evident that (a) telicity affects the aspectual choices of children and adults, (b) perfective aspect is selected for telic events adult-like by children from the age of 8 and (c) imperfective aspect is used for atelic activities by children as young as 5 yrs old.

\section{Motion Events and Aspect}

For the event type comparisons (telic vs. atelic) in the aspectual marking of motion verb constructions we performed two-way group-independence chi- 
square tests. The comparisons show that the event type the participants were shown significantly affects the aspectual choice of all child groups and adults (5-6 yrs old: $\chi^{2}=10.919, \mathrm{df}=1, p=.001 ; 6-7$ yrs old: $\chi^{2}=10.989, \mathrm{df}=1, p=.001 ; 7-8$ yrs old: $\chi^{2}=7.614, d f=1, p=.006 ; 8-9$ yrs old: $\chi^{2}=21.658, d f=1, p=.000 ; 9-10$ yrs old: $\chi^{2}=34.998, \mathrm{df}=1, \mathrm{p}=.000$; Adults: $\chi^{2}=20.198, \mathrm{df}=1, \mathrm{p}=.000$ ).

Figure 3 presents the percentages of the aspectual marking for motion VPs of each age group when they were provided with a telic event.

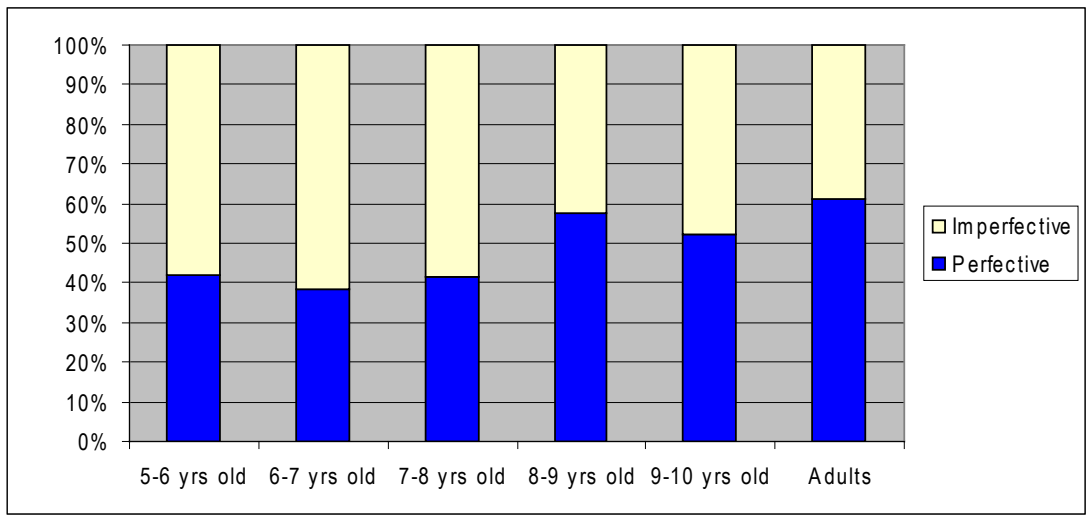

Figure 3. Aspectual Marking: Motion Telic Events

The data reported in Figure 3 show that children appear to be confused over the aspectual marking of motion telic events, while adults significantly prefer using perfective aspect. In particular, the use of imperfective is predominant for the youngest child groups. The 6-7 yrs old group significantly selects imperfective aspect, while the rest of the child groups are undetermined and perform at chance level indicating the acquisitional difficulty posed by telic motions. These observations were statistically supported by one-waygoodness-of-fit chi-square tests ( $5-6$ yrs old: $\chi^{2}=2.701, \mathrm{df}=1, \mathrm{p}=.100 ; 6-7 \mathrm{yrs}$ old: $\chi^{2}=5.538, \mathrm{df}=1, \mathrm{p}=.019 ; 7-8$ yrs old: $\chi^{2}=3.115, \mathrm{df}=1, \mathrm{p}=.078 ; 8-9$ yrs old: $\chi^{2}=2.843, \mathrm{df}=1, \mathrm{p}=.092 ; 9-10$ yrs old: $\chi^{2}=.261, \mathrm{df}=1, \mathrm{p}=.610 ;$ Adults: $\chi^{2}=4.840$, $\mathrm{df}=1, \mathrm{p}=.028)$.

Figure 4 presents the percentages of the aspectual marking for motion VPs of each age group when they were provided with an atelic event.

The data reported in Figure 4 show that, unlike the findings in the telic condition, in the atelic condition children perform adult-like is selecting the imperfective to describe the atelic motion events $\left(5-6\right.$ yrs old: $\chi^{2}=35.438, \mathrm{df}=$ $1, \mathrm{p}=.000 ; 6-7$ yrs old: $\chi^{2}=39.112, \mathrm{df}=1, \mathrm{p}=.000 ; 7-8$ yrs old: $\chi^{2}=27.174, \mathrm{df}=1$, $\mathrm{p}=.000 ; 8-9$ yrs old: $\chi^{2}=23.450, \mathrm{df}=1, \mathrm{p}=.000 ; 9-10$ yrs old: $\chi^{2}=57.110, \mathrm{df}=1$, $\mathrm{p}=.000$; Adults: $\chi^{2}=17.280, \mathrm{df}=1, \mathrm{p}=.000$ ). 


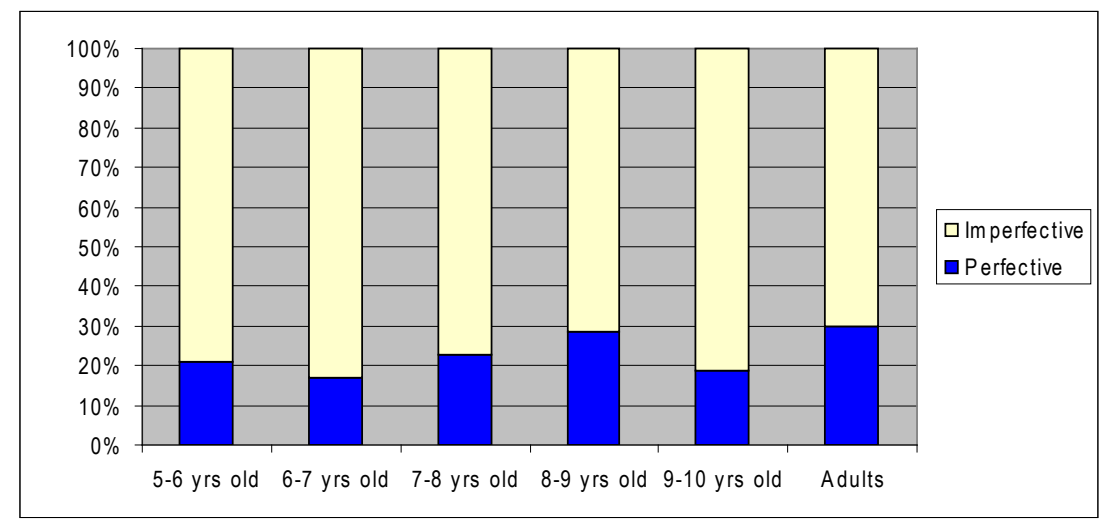

Figure 4. Aspectual Marking: Motion Atelic Events

The between group comparisons for the telic condition show the children's performance is quite uniform. For the 6-7 yrs old group comparisons show a significant difference to the two oldest age groups (8-9 and 9-10 yrs old groups). Also, the 7-8 yrs old children appear to differ to the 8-9 yrs old ones. The age of 8 is of importance for the acquisition of telicity for motion verbs since it is from that age on that we get adult-like aspectual preferences by the children. In the atelic condition, there is a similar performance across the groups and the preference of imperfective mapping on atelic motion events appears set early on in acquisition. The 6-7 yrs old group differs to the 8-9 yrs old group and adults. Quite interestingly, as for activity verbs, the 9-10 yrs old group overuses imperfective aspect, which is the target aspectual choice, and, thus, appears to be significantly different to the 8-9 yrs old group and adults.

The between verb-type comparisons per event type appear in Table 1. In the telic condition, the two verb categories are differentiated by children with the exception of 6-7 and 8-9 yrs old children, but crucially not by adults who appear not equally sensitive. In the atelic condition, both verb types are treated similarly by all groups with the exception of 7-9 yrs old children who significantly distinguish between the two. Overall, children are more responsive to VP differences.

To summarize, the examination of aspectual marking for motion verbs makes evident that (a) telicity affects the aspectual choices of children and adults, (b) perfective aspect is selected for telic events by adults but children do not attain the adult performance not even up to the age of 10 , (c) imperfective aspect is used for atelic activities by all child groups and adults and (d) children are sensitive to the verb type when selecting aspect for telic events. These findings are pointing to the difficulties motion verb constructions pose in acquisition and are in accordance to our predictions. 
Table 1.

Between Verb-Type Comparisons: Aspectual Marking

\begin{tabular}{|l|c|c|}
\hline \multirow{2}{*}{ Groups } & Telic Event *Aspect & Atelic Event * Aspect \\
\cline { 2 - 3 } & Activity vs. Motion Verbs & Activity vs. Motion Verbs \\
\hline 5-6 yrs old & $\chi^{2}=8.019, \mathrm{df}=1, \mathrm{p}=.005$ & $\chi^{2}=2.058, \mathrm{df}=1, \mathrm{p}=.151$ \\
\hline 6-7 yrs old & $\chi^{2}=1.235, \mathrm{df}=1, \mathrm{p}=.267$ & $\chi^{2}=2.932, \mathrm{df}=1, \mathrm{p}=.087$ \\
\hline 7-8 yrs old & $\chi^{2}=5.130, \mathrm{df}=1, \mathrm{p}=.024$ & $\chi^{2}=5.008, \mathrm{df}=1, \mathrm{p}=.025$ \\
\hline 8-9 yrs old & $\chi^{2}=.089, \mathrm{df}=1, \mathrm{p}=.765$ & $\chi^{2}=4.392, \mathrm{df}=1, \mathrm{p}=.036$ \\
\hline 9-10 yrs old & $\chi^{2}=35.133, \mathrm{df}=1, \mathrm{p}=.000$ & $\chi^{2}=.024, \mathrm{df}=1, \mathrm{p}=.876$ \\
\hline Adults & $\chi^{2}=1.087, \mathrm{df}=1, \mathrm{p}=.297$ & $\chi^{2}=.407, \mathrm{df}=1, \mathrm{p}=.523$ \\
\hline
\end{tabular}

Telic Events and Complement Use

In the following set of data, we examine the use of complement in the telic condition when it is paired with perfective aspect. Figure 5 presents the percentages of DP-use in perfective VPs of each age group when they were provided with a telic activity event.

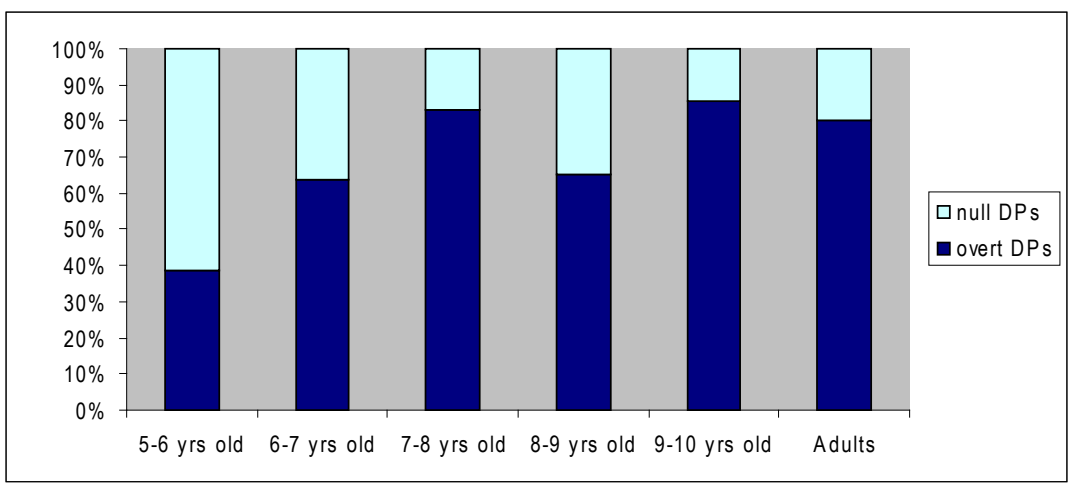

Figure 5. Telic Activities: Perfective Aspect \& Complement Use

The data reported in Figure 5 suggest that the 5-6 year old children avoid the use of overt complement DP for telic activities, while the 6-7 year old children show optionality in the overt vs. null use of DPs. From 7 years-old and onwards, however, the children acquire the adult performance in marking telicity with the use of overt complements as endpoints. These observations were statistically supported by one-way goodness-of-fit chi-square tests ( $7-8$ yrs old: $\chi^{2}=31.113$, $\mathrm{df}=1, \mathrm{p}=.000 ; 8-9$ yrs old: $\chi^{2}=7.530, \mathrm{df}=1, \mathrm{p}=.006 ; 9-10$ yrs old: $\chi^{2}=64.286$, $\mathrm{df}=1, \mathrm{p}=.000 ;$ adults: $\chi^{2}=27.842, \mathrm{df}=1, \mathrm{p}=.000$ ). 
Figure 6 presents the percentages of PP-use in perfective VPs of each age group when they were provided with a telic motion event.

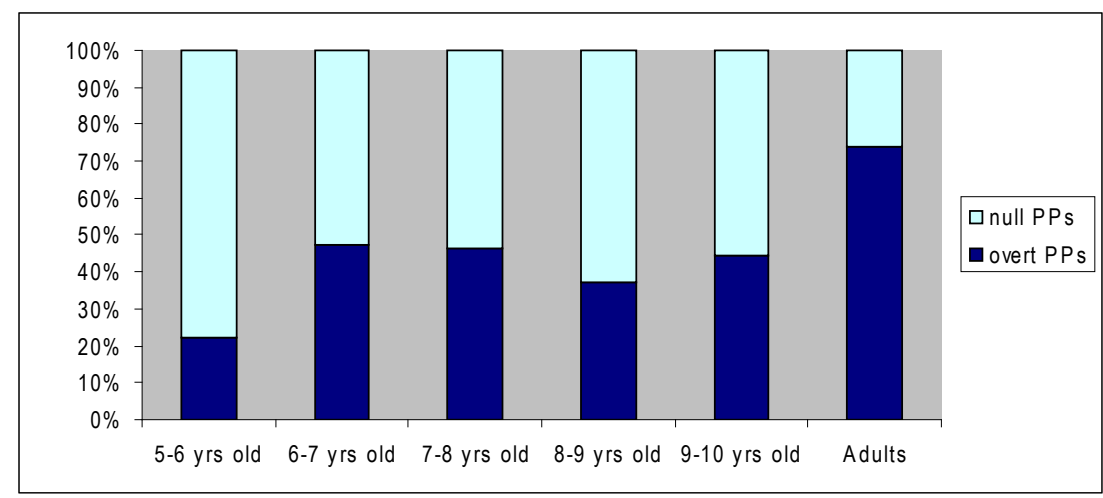

Figure 6. Telic Activities: Perfective Aspect \& Complement Use

Turning to telic motion events, the data reported in Figure 6 suggest that the use of complement PPs is differentiated to that of DP production. The 5-6 year old children show very restricted use of PPs, which becomes optional for the rest of the L1 learners, while adults use overt PPs to indicate endpoints and encode telicity in motion events. These observations were statistically supported by one-way goodness-of-fit chi-square tests $\left(5-6\right.$ yrs old: $\chi^{2}=13.886, \mathrm{df}=1, \mathrm{p}=$ .000 ; adults: $\chi^{2}=13.787, \mathrm{df}=1, \mathrm{p}=.000$ ).

Turning to the between verb-type comparisons, Table 2 presents two-way group-independence chi-square tests to determine the role of telicity for each verb category in relation to the complement production when perfective aspect was provided by the participants. Children from the age of 7 and up do differentiate between the two verb-categories. Adults, on the other hand, when selecting perfective aspect do not make the same distinction.

Table 2.

Between Verb-Type Comparisons: Perfective VPs \& Complement Use

\begin{tabular}{|l|l|}
\hline \multirow{2}{*}{ Groups } & Telic Event \\
\cline { 2 - 2 } & Activity vs. Motion Verbs \\
\hline 5-6 yrs old & $\chi^{2}=2.426, \mathrm{df}=1, \mathrm{p}=.119$ \\
\hline 6-7 yrs old & $\chi^{2}=2.058, \mathrm{df}=1, \mathrm{p}=.151$ \\
\hline 7-8 yrs old & $\chi^{2}=16.850, \mathrm{df}=1, \mathrm{p}=.000$ \\
\hline 8-9 yrs old & $\chi^{2}=12.263, \mathrm{df}=1, \mathrm{p}=.000$ \\
\hline 9-10 yrs old & $\chi^{2}=37.677, \mathrm{df}=1, \mathrm{p}=.000$ \\
\hline Adults & $\chi^{2}=.815, \mathrm{df}=1, \mathrm{p}=.367$ \\
\hline
\end{tabular}


In sum, the production results show that for L1 learners activity verbs select perfective aspect and complements more strongly than motion verbs. The use of the imperfective for both verb types is preferred by the 5-7 year old children. The 9-10 year old learners, on the other hand, distinguish between activity and motion verbs in marking telicity and show adult like performance with regard both to aspectual marking and complement use for activities but not for motion events. Overall morphological aspect is used to denote telicity earlier than complement DPs or PPs in the acquisition of telicity.

\section{Conclusion}

This study examined the production of telicity by L1 learners of Greek so as to identify the nature of the relation between aspect and telicity by comparing evidence drawn from activity and motion verb constructions. The production results show that aspect is found to operate in relation to telicity. Perfective aspect is used to mark telicity on both activity and motion events but poses difficulties developmentally especially in the case of the latter. Imperfective aspect, on the other hand, is related to atelic events for both verb categories and is in place earlier in acquisition than perfective aspectual marking. The results on the joint use of perfective aspect and overt complements for telic events indicate two separate developmental milestones for each verb category. Learners aged 7 and up develop an adult-like preference for perfective activity VPs with overt complements but this preference does not develop for the motion construction even at the age of 10 .

\section{Acknowledgments}

This research has been co-financed by the European Union (European Social Fund - ESF) and Greek national funds through the Operational Program "Education and Lifelong Learning" of the National Strategic Reference Framework (NSRF) - Research Funding Program: Heracleitus II. Investing in knowledge society through the European Social Fund. 


\section{References}

Borik, O. 2006. Aspect and reference time. OUP.

Chila-Markopoulou, D. and A. Mozer. 2001. Telicity and referentiality in the VP of Modern Greek: Aspect and Determiner. In Y. Agouraki et al. (eds.), Proceedings of the 4th International Conference on Greek Lingustics. Nicosia: University Studio Press, 138-145.

Depreatere, I. 2007. (A)telicity and Intentionality. Journal of Linguistics 45.2: 243-269.

Dowty, D. 1979. Word Meaning and Montague Grammar. Dordrecht: Reidel.

Kaltsa, M. 2012. The acquisition of telicity in the native language. AUTH: Unpublished PhD Thesis.

Katis, D. 1984. The acquisition of the Modern Greek verb with special reference to the imperfective past and perfect classes. Ph.D. Dissertation. University of Reading.

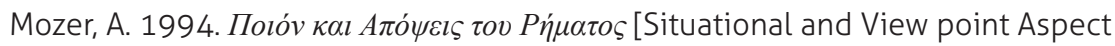
of the Verb]. Athens: Parousia.

Ramchand, G. and P. Svenonius. 2002. The Lexical Syntax and Lexical Semantics of the Verb Particle Construction. WCCFL 21 Proceedings. University of Tromsø: Cascadilla Press, 387-400.

Rothstein, S. 2002. What is lexical aspect? Talk given at Trans Seminar of Syntax and Semantics, UiL OTS, Utrecht University.

Schultz, P. and A. Wittek. 2003. Opening doors and sweeping floors: What children with specific language impairment know about telic and atelic verbs. 
In B. Beachley et al. (eds.), Proceedings of 27 BUCLD. Somerville: CascadillaPress, 727-738.

Smith, C. 1991. The parameter of Aspect. Studies in Linguistics and Philosophy 43. Dordrecht, Boston, London: Kluwer Academic Publishers.

Tsimpli, I.M. 1992/1996. The Prefunctional Stage of First Language Acquisition: A crosslinguistic Study. Ph.D. Dissertation, UCL. New York and London: Garland.

Tsimpli, I.M. and D. Papadopoulou. 2006. Aspect and argument realization : A study on antecedentless null objects in Greek. Lingua 116, 1595-1615.

Tsimpli, I.M. and D. Papadopoulou. 2009. Aspect and the Interpretation of Motion Verbs in L2 Greek. In N. Snape, Y.I. Leung and M. Sharwood Smith (eds), Representational Deficits in SLA. John Benjamins, 187-227.

Van Hout, A. 1998. On the role of direct objects and particles in learning telicity in Dutch and English. In A. Greenhill et al. (eds.), Proceedings of 22 BUCLD. Somerville: CascadillaPress, 397-408.

Van Hout, A. 2000. Event semantics in the lexicon-syntax interface: Verb frame alternations in Dutch and their acquisition. In C. Tenny and J. Pustejovsky (eds.), Events as grammatical objects. Stanford: CSLI, 239-282.

Van Hout, A. 2003. Acquiring telicity crosslinguistically: On the acquisition of telicity entailments associated with transitivity. In M. Bowerman and P. Brown (eds.), Crosslinguistic perspectives on argument structure: Implications for learnability. Hillsdale: Lawrence Erlbaum.

Vendler, Z. 1976. Verbs and times. Linguistics in Philosophy. Ithaca: Cornell UP.

Wagner, L. 2006. Aspectual Bootstrapping in Language Acquisition: Telicity and Transitivity. Language Learning and Development 2(1), 51-76.

Wagner, L. 2010. Inferring Meaning from Syntactic Structures in Acquisition: The Case of Transitivity and Telicity. Language and Cognitive Processes 25, 13541379. 